\title{
CONTEXTOS AUGUSTEOS EN AUGUSTA EMERITA
}

\author{
AUGUSTEAN CONTEXTS IN AUGUSTA EMERITA
}

\author{
MACARENA BUSTAMANTE ÁLVAREZ ${ }^{1}$ \\ Instituto de Arqueología de Mérida, CSIC
}

A pesar de la fundación augustea de la ciudad (según los autores clásicos Dion Casio, Hist. Rom. 53, 25, 2), Augusta Emerita, a día de hoy, presenta pocas evidencias cerámicas que den prueba de ello, al menos, en lo que se refiere a los primeros años del Principado.

Desde el punto de vista ceramológico, que es el que centra nuestra atención, únicamente son tres los conjuntos exhumados a los que se les puede atribuir cronología augustea. Lo normal sería la presencia de abundantes conjuntos que denoten una importante labor constructiva para erigir esta ciudad. Sin embargo, se nos presenta un panorama ligeramente opuesto, donde la ausencia de estas facies cronológicas quizás sea la señal de una lenta génesis en el diseño del entramado urbano emeritense.

En este punto, analizaremos tres contextos dispares, en cuanto funcionalidad, pero bastante homogéneos a la hora de generarnos una sucinta idea de cuál fue el panorama inicial en clave ceramológica. Un contexto forense (el del templo de la c/Viñeros), uno artesanal (el de la figlina de la Escuela de Hostelería) y para finalizar uno funerario (el del complejo de la c/ Almendralejo 41) serán nuestro apoyo en este análisis $^{2}$. De los tres, los dos primeros ya han sido publicados; el primero por los compañeros Aquilué y Bello (2009) mientras que el segundo fue abordado por la firmante (Bustamante y Heras, 2013). El interés de

\footnotetext{
1. Programa JAE-DOC, financiado por el FSE.
}

2. Recientemente vio la luz un trabajo sobre los contextos cerámicos de los Columbarios de Mérida en un volumen específico sobre Contextos cerámicos de época augustea en el Mediterráneo occidental (Bello y Márquez, 2010). A pesar de que este conjunto se planteaba como uno de los «primeros contextos romanos de la ciudad»-tal y como se expresa en el título de su intervención- (Bello y Márquez, 2010, 409) la aparición de determinadas formas cerámicas (caso de formas Drag. 35-36), nos inducen a categorizar este contexto como un conjunto de conformación vespasianea más que de una lenta génesis formativa desde época augustea. Por ello este trabajo no será valorado en este estudio. este trabajo, además de establecer los rasgos básicos de cuáles fueron las cerámicas consumidas en la ciudad durante estos primeros momentos, redunda en presentar un nuevo conjunto hasta el momento inédito, el de la c/Almendralejo $41^{3}$.

Con todo ello pretendemos establecer algunas señas de cuál fue el comportamiento vascular en los primeros de vida de la Colonia, temática que hasta el momento ha sido valorada sólo parcialmente y no de manera global como es el trabajo que ahora nos centra.

\section{LOS ESTRATOS CONSTRUCTIVOS DEL TEM- PLO DE LA C/VIÑEROS}

Uno de los conjuntos que más evidencias vasculares han aportado para esos momentos iniciales del municipio, son los estratos constructivos del templo de la c/ Viñeros. Esta construcción, ubicada en la plataforma occidental del foro municipal, ha sido ya objeto de estudio, no sólo en clave arquitectónica/funcional (Palma, 2009), sino de igual modo ceramológica (Aquilué y Bello, 2009, 417-425) ${ }^{4}$.

La propia naturaleza de este contexto, en el mismo corazón de la ciudad, y en zona claramente pública, nos hace usarlo como referente para estos primeros momentos. A modo de síntesis, podemos decir que es un contexto augusteo modélico ya que recoge la cultura material que circuló durante los primeros momentos del Imperio en el suroeste peninsular, de ahí nuestro

3. Agradecemos las facilidades prestadas al codirector de la intervención del solar F.J. Heras. Este estudio ha sido posible gracias a su constante amabilidad así como al permiso otorgado por el Consorcio de Mérida (n. permiso 2011/478) para el estudio del mobiliario cerámico.

4. En este punto nos limitamos a recoger la publicación por los compañeros realizada que contiene el grueso de lo exhumado. Por ello, a partir de su publicación efectuaremos algunas reflexiones de conjunto. 


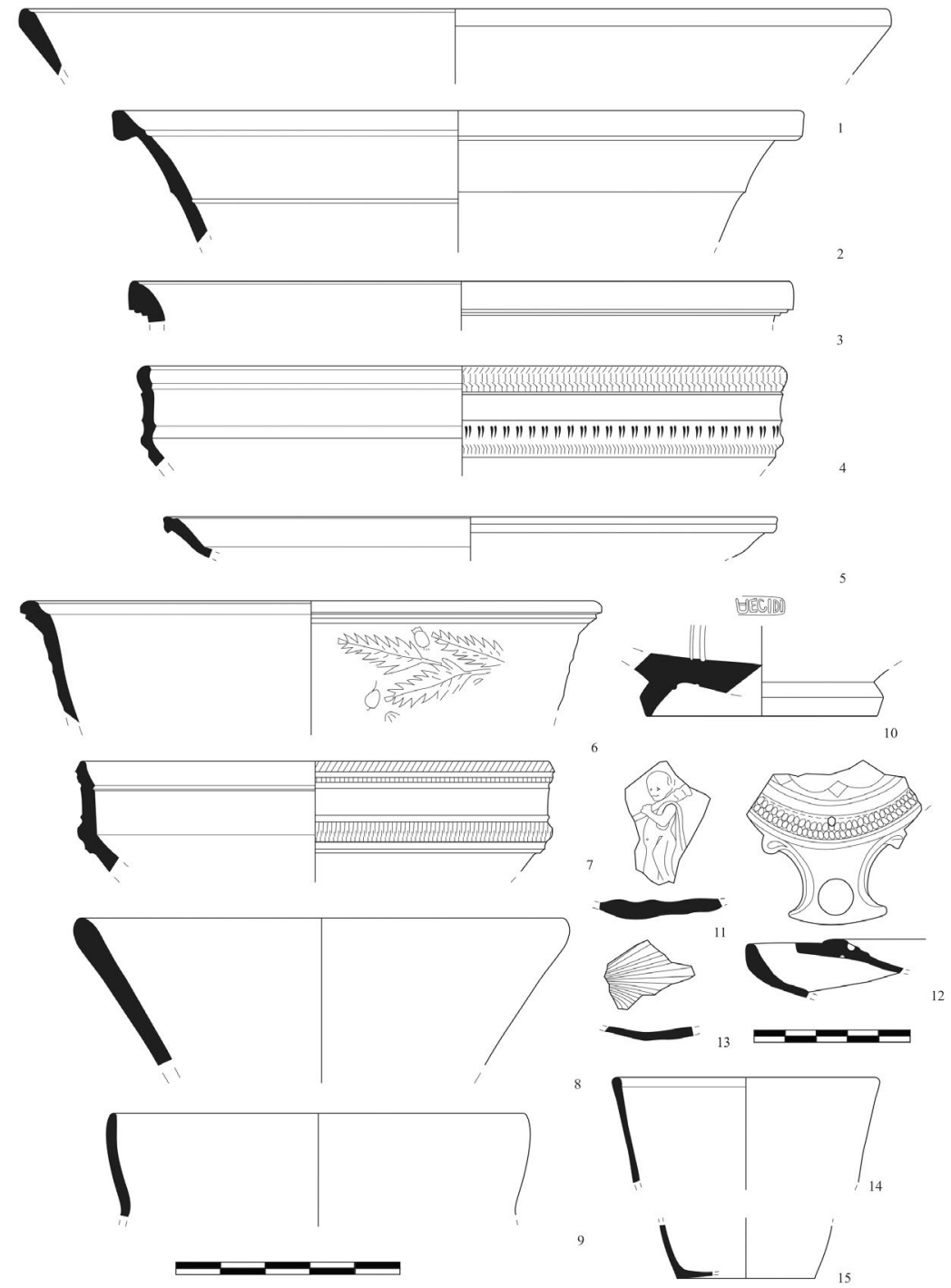

Figura 1: Materiales cerámicos procedentes de la cimentación del templo de la c/Viñero (a partir de los dibujos publicados por Aquilué y Bello, 2009, cortesía F. Palma).

interés. Incidimos en el hecho de que este patrón será reiterativo en los otros conjuntos.

Según el estudio realizado, estos contextos que detallaremos a continuación, permiten fechar la construcción del templo en los primeros decenios del I d.C. (Aquilué y Bello, 2009, 421), momento cronológico que centra nuestro trabajo.

Al igual que en los otros conjuntos que se tratarán, los materiales que nos ofrecen los datos para esta datación son las sigillatas. Según lo recogido por los compañeros, el grueso de las piezas localizadas serían las sigillatas itálicas procedentes, en su mayoría, del taller de Arezzo.

Tipológicamente las piezas publicadas nos permiten hablar de un servicio muy heterogéneo en el que predominan las copas Consp. 14.1 (Fig. 1, n. 2-3) o 22. 1 (Fig. 1, n. 4 y 7). Entre los platos destacan una forma Consp. 1.1 .3 y una 2.3 (Fig. 1, n. 1 y 5 respectivamente). También se localiza una gran copa de variante indeterminada de R. 9 (Fig. 1, n. 6), adscritas por sus investigadores a la forma Consp. 3, con decoración de amapolas en movimiento que, iconográficamente, atribuimos al taller de Tigranus (Dragendorff y Watzinger, 1948, 231, n. 549).

A este repertorio le debemos unir dos piezas selladas publicadas, una de cartela rectangular en la que se lee HERT (Hertorius, O.C.K. n. 932) y otra sobre copa indeterminada en la que se plasma (.)HEGIDI (L. Iegidius, O.C.K. n. 932) (Fig. 1, n. 10). Ambos artesanos aparecen cronológicamente insertos entre el cambio de era y el periodo tardoaugusteo.

Al analizar este contexto podemos percibir una pugna entre la Península Itálica y la Bética por encabezar la procedencia de los productos exportados a la Lusitania. El mundo itálico, además de las sigillatas ya valoradas, aporta otros elementos vasculares. Para la c/Viñeros, se han individualizado otros tipos cerámicos. Las paredes finas del conjunto, aunque son escasas, proceden en su totalidad de la Península Itálica, hecho que no nos debe sorprender pues en estos 


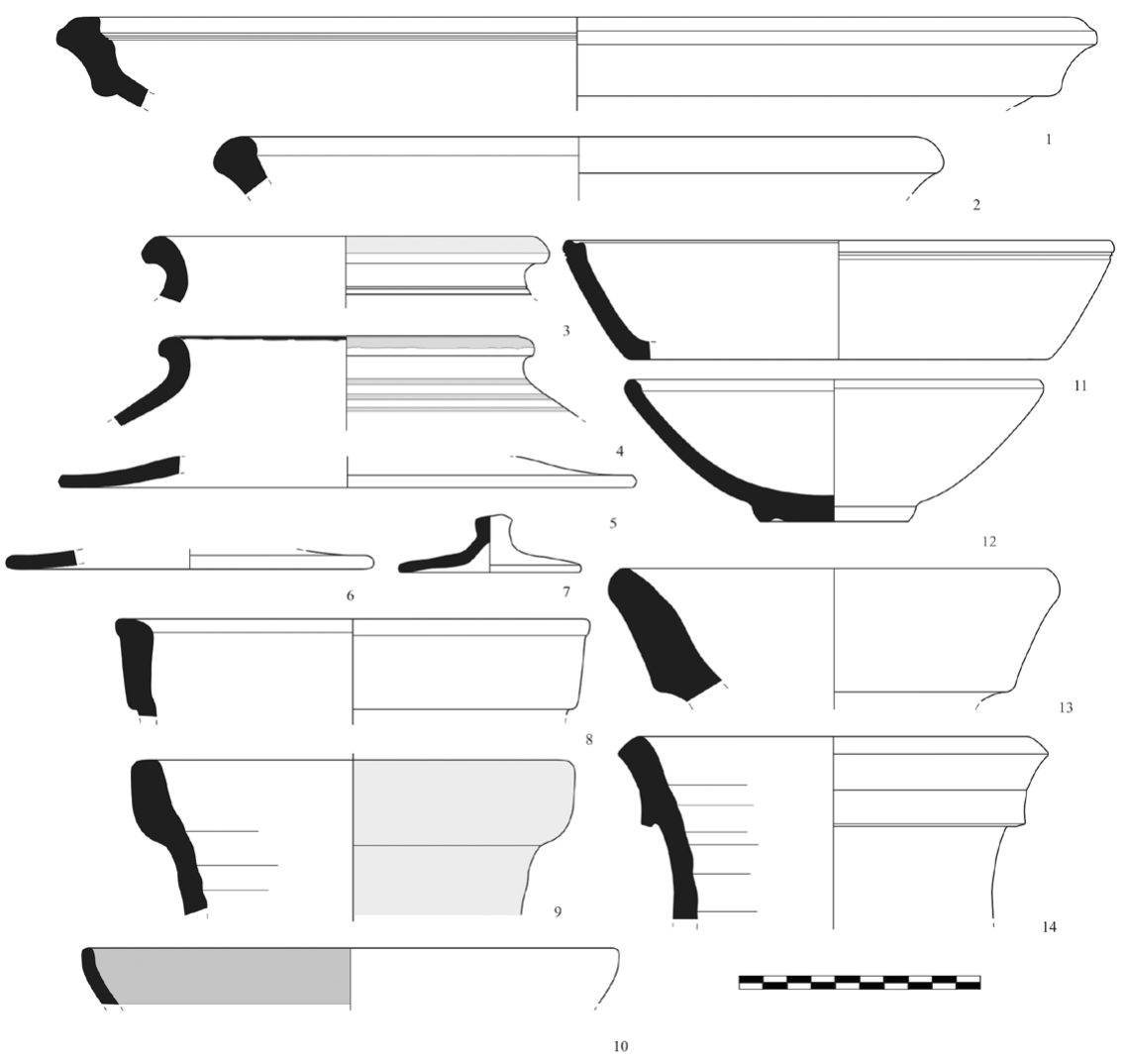

Figura 2: Materiales cerámicos procedentes de la cimentación del templo de la c/Viñero (a partir de los dibujos publicados por Aquilué y Bello, 2009, cortesía F. Palma).

momentos los talleres peninsulares no estarían activos (Mayet, 1975, 125) 5 . Entre las piezas plasmadas, atribuidas a formas Mayet 8 y 14 (Aquilué y Bello, 2009, 421), destaca un borde que asociamos a la producción de formas Ricci $1 / 20$ de procedencia campana (Fig. 1, n. 9), así como un borde y fondo de cubilete (Fig. 1, n. 14-15).

En estos momentos también aparecen piezas de engobe interno rojo pompeyano, más concretamente de los tipo Goud. 15/16 que apoyan una cronología temprana del conjunto (Fig. 2, n. 10). El repertorio de lámparas itálicas es muy escaso, con la aparición de dos fragmentos de disco, uno con decoración de erote portando atributos hercúleos, más concretamente la

\footnotetext{
5. Hoy en día se conoce un nuevo centro productor de cerámicas de paredes finas, el Parque Nueva Granada (Granada). Sus investigadores lo fechan en las décadas centrales del I a.C. en los avances hasta el momento publicados (Peinado et alii, 2010, 35-36; Ruiz Montes et alii, 2013). Esperamos que un futuro, cuando concluya su estudio, se justifique contextual y cuantitativamente dicha producción que, sin lugar a dudas, suponen un importante avance en el conocimiento de estas formas cerámicas hasta el momento casi exclusivas de la Península Itálica. A pesar de ello, los contextos de consumos béticos, como ya avanzaba Mayet, registran un abastecimiento itálico y no local-regional, hecho tradicionalmente asociado a la ausencia de talleres productivos en fechas tan tempranas.
}

leonté y el cayado (Fig. 1, n. 11) y otro con estrías que asociamos a una posible venera (Fig. 1, n. 13). Para finalizar con este apartado también se localiza un pico de lucerna triangular con margo enjoyado y disco con decoración imprecisa que adscribimos al tipo Dr. 9a (Fig. 1, n. 12).

Sorpresivamente se da la ausencia de ánforas itálicas dando la sensación de que el abastecimiento de esta categoría es elevadamente bético. Entre las ánforas béticas localizadas se encuentran formas de Dr. 7/11 de borde con tendencia vertical (Aquilué y Bello, 2009, lám. 19, n. 3) -Fig. 2, n. 14- así como una Haltern 70 del valle del Guadalquivir (Aquilué y Bello, 2009, lám. 19, n. 4 y lám. 24, n. 12) -Fig. 2, n. 8 y 13-. Hay una pieza engobada incluida inicialmente en el grupo de las comunes (Aquilué y Bello, 2009, 418, lám. 24, n. 14) -Fig. 2, n. 9-. Su grosor de pared, el borde rectangular con escalón interno y su engobe blanquecino, son algunas de las características definitorias de la producción de ánforas locales asociadas a variantes de las Haltern 70 (Bustamante y Heras, 2013) por lo que estaríamos ante una ánfora local y no una producción común.

Entre las producciones béticas presentes, además de las ánforas antes comentadas, destaca un fragmento de copa de imitación tipo Peñaflor borde Mart. 5/ imitación Conps. 7 con labio simple y de tendencia apuntada (Aquilué y Bello, 2009, lám. 18, n. 5) -Fig. 1, n. $8-$ 
En el apartado de las comunes, aunque el grueso es local-regional, hay algunas piezas procedentes de la Bética, destacándose los morteros tradicionalmente asociados a dicha región (Sánchez, 1995, 251)-Fig. 2, n. 1 y $2-$. La aparición de estos tipos con similar morfología es continua en contextos de la primera edad julio-claudia tanto en Mérida como en otros puntos de la Lusitania. Conimbriga (Alarção et alii, 1976), Mesas do Castelinho (Fabião y Guerra, 1993, 275), Castelo de Lousa (Wahl, 1985, 163) o Braga (Morais, $2004,567)$ son otros enclaves en territorio luso donde se ha constatado esta producción (para más datos sobre su distribución nos remitimos a la obra de J. C. Quaresma, 2006).

Para finalizar, el grupo de las producciones locales es poco variado. Además del ánfora antes comentada, son constantes piezas de tradición indígena con decoración a bandas pintadas tanto en este conjunto como en los que valoraremos a continuación (Aquilué y Bello, 2009, lám. 21, n. 6 y lám. 23, n. 9-10) -Fig. 2, n. 3-4-. Otros contextos dispersos por el territorio emeritense también nos hablan de una larga tradición de estas cerámicas que llegan hasta la mitad del I d.C. (Bustamante, 2009, 260-261) aunque su génesis debe retrotraerse al mundo indígena (Rodríguez Díaz, 1995, lám. 5 y 6). Además de este acabado de larga tradición, las formas con bordes redondeados y caídos nos recuerdan también a las urnas protohistóricas que inundan esta zona.

Para finalizar con estos contextos son muchas las piezas comunes plasmadas (Aquilué y Bello, 2009, 418). Aunque no se precisa de manera individual su origen se observa una serie de rasgos similares a las piezas producidas en la figlina de la Escuela de Hostelería que tratamos a continuación. La aparición de páteras con paredes de tendencia vertical, cuencos de bordes engrosados y bífidos o las tapaderas (Fig. 2, n. 4-7 y 11-12) suelen ser algunos de los indicios para adscribirlo al modo productivo local. Así mismo la escasa aparición de jarras (Aquilué y Bello, 2009, lám. 23 , n. 6, 8 y 9-10) también puede ser una consecuencia directa de la ausencia de las mismas en contextos productivos.

\section{LA FIGLINA DE LA ESCUELA DE HOSTELE-} RÍA DE MÉRIDA. UN COMPLEJO ALFARERO AL SERVICIO DE LA CONSTRUCCIÓN DE LA COLONIA

En nuestro intento de valorar contextos de génesis y praxis variada, hemos decidido que, el contexto antagónico al espacio público anteriormente tratado, sería una zona artesanal. Para ello, hemos usado uno de los espacios artesanales recientemente hallado, el solar de la Escuela de Hostelería. Su ubicación, en la margen derecha del río Guadiana y en una zona ligeramente alejada del corazón político de la ciudad, hacía presagiar este hallazgo.
En dicho solar apareció un complejo alfarero con varios hornos que suponían la continuidad a una zona alfarera de larga tradición, remontable a época orientalizante (Jiménez et alii, 2013 y Bustamante y Heras, 2013). Uno de esos hornos, asociado a su primera fase, aparecía amortizado por un conjunto cerámico tardoaugusteo que apuntaba que el uso de esa estructura había sido anterior a esta época (Heras, Jiménez y Bustamante, e.p.). La importancia de esta intervención reside en que, además de ser un conjunto cerrado de génesis temprana, nos habla de un tipo de manufactura, hasta el momento, no documentada para época augustea, las ánforas.

La amortización de este conjunto se conformaba no sólo de materiales cerámicos alóctonos al lugar y, presumiblemente consumidos por los artesanos de la instalación, sino que además se componía de desechos alfareros generados en el seno de la figlina.

Entre los materiales localizados destacamos un vaso Aco en paredes finas de procedencia noritálica (Schindler, 1980; Lavazzari, 1987) -Fig. 3, n. 6-. Recordemos sucintamente que los vasos tipo Aco se ubican cronológicamente en época proto y medio augustea (Mayet, 1975, 26-27 y 36). Las paredes finas itálicas se acompañan de un fondo plano de un cubilete de cronología indeterminada, que podríamos asociar apriorísticamente a una forma Mayet XXXIII (Fig. 3, n. 8). La aparición de paredes finas foráneas acapara el mercado en un momento en el que los talleres emeritenses no están activos.

Otras de las piezas usuales en estos momentos son las cerámicas de imitación tipo Peñaflor de los tipos Mart. I así como Mart. III de procedencia bética (Fig. 3, n. 3). La forma Mart. I, que se inspira en modelos formales itálicos de época inicial, más concretamente la forma Consp. 8, también apunta a una génesis temprana del conjunto.

También aparece un galbo de sigillata itálica de procedencia aretina posiblemente un cáliz R. 5 (Fig. 3 , n. 5). En él se vislumbran los miembros inferiores inclinados y en movimiento de un individuo, que quizás se encuentre tocando algún instrumento. Buscando paralelos de la representación encontramos un ejemplar similar en el que se aprecia la parte superior de un sátiro tocando flauta doble. Este ejemplar fue atribuido al taller de M. Perennius Bargathes, más concretamente a su Zyklus VII, Reihe C 1-3 (Dragendorff y Watzinger, 1948, 198, n. 229). Recordemos que el periodo de actividad de este alfarero va en perfecta consonancia con la cronología apuntada para la amortización. Dentro de las sigillatas itálicas, se localiza un borde de una copa Consp. 14.1 (Fig. 3, n. 4) así como un fondo de plato de indeterminado (Fig. 3, n. 7).

Junto al repertorio de vajilla fina itálica y bética, aparecen cerámicas comunes que, macroscópicamente, presenta rasgos béticos. Más concretamente, nos referimos a morteros con amplia solapa exterior, bordes sinuosos y estriado interior que tradicionalmente 

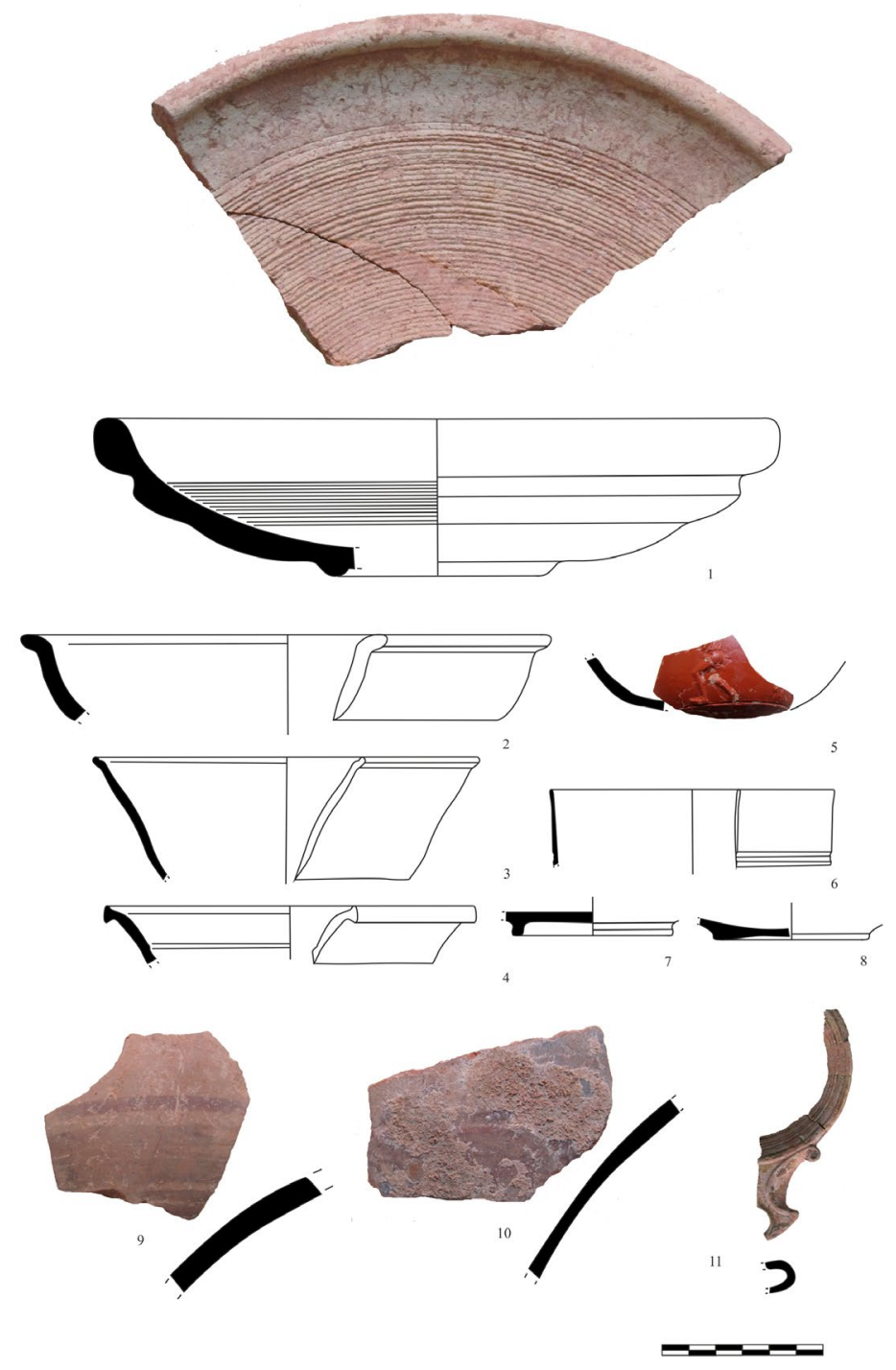

Figura 3: Cerámicas importadas localizadas en la figlina de la Escuela de Hostelería (a partir de Bustamante y Heras, 2013).

se han asociado a la Bética (Sánchez, 1995, 251) (Fig. 3, n. 1).

Además de por la vajilla fina y algunas piezas comunes, la temprana cronología por la que apostamos se apoya en la aparición de otros productos de procedencia itálica (Fig. 3, n. 2). Un borde redondeado de plato de engobe rojo interno pompeyano itálico del tipo Luni 5 también refuerza esta fecha. Para finalizar con las piezas foráneas localizamos un fragmento de lucerna con pico triangular Loeschke Ib (Fig. 3, n. 11).

Además de estas piezas de claro origen foráneo, en este contexto se localizaron otros elementos localesregionales y otros producidos en los hornos ubicados en sus inmediaciones, pues como ya se advirtió previamente, la misma estructura del horno fue usada como testar para verter los detritos generados en el mismo complejo productivo.

Dentro del compendio de cerámicas regionales se han localizado algunos ejemplos de cerámicas pintadas de tradición indígena que, aunque hunden sus raíces en época prerromana, están presentes en Mérida y su territorium desde época muy temprana (Fig. 3, n. 9-10).

Junto a las piezas importadas, valoraremos las producidas en este taller que se pueden resumir en: cerámicas comunes y ánforas. Ambas categorías presentan rasgos muy concretos que apuntan a una inspiración bética. Groso modo, a falta de análisis arqueométricos, las cerámicas localizadas presentan pastas de coloración muy rojiza, poco depuradas, con desgrasantes calcáreos de granulometría media-gruesa pudiendo contar su acabado con una capa de fino engobe y, muy esporádicamente, bandas pintadas bícromas (vinosas y blancas).

Cuantitativamente, las piezas que más se ha documentado en estos contextos son las ánforas. La producción de esta categoría vascular no es nueva en suelo emeritense. Desde el año 2005, se tiene constancia de una producción local de ánforas muy similares a las Haltern 70 canónicas gracias a la intervención en una 
figlina en la c/Ana-Avda. Lusitania (Alba y Méndez, 2005, 389-390, lám. 34-35). Morfológicamente estos autores establecieron una serie de variantes en función de su tamaño y borde, siendo su aspecto final de tendencia ovoide (Alba y Méndez, 2005, 390).

La producción constatada en la Escuela de Hostelería reproduce, de manera más libre, las manufacturadas del taller de la Avda. Lusitania. De nuevo vemos variantes en cuanto a su tamaño, aparece una de mayores dimensiones aderezada con una engalba blanquecina muy líquida (que denominamos tipo I) y otra más pequeña sin tratamiento externo (que denominamos tipo II). Morfológicamente, las ánforas producidas en Mérida, tuvieron como referente claro las producciones béticas, más concretamente, la forma Haltern 70 . Los bordes presentan un perfil rectangular con leve escalón en su zona interior. El desarrollo vertical del borde también varía en cuanto a tamaño (Fig. 4, n. 9 y 13). La libre interpretación de las ánforas béticas viene de la mano de la aparición indistinta de pivotes macizos y huecos.

Además de la cronología aportada por el contexto, esta imitación también puede apuntar a esta fase tan temprana. La constatación de las ánforas prototípicas oriundas de la Bética en los campamentos de Haltern, así como en algunos pecios hallados, han permitido acotar su vida, desde mediados del I a.C. hasta época Flavia (Martin-Kilcher, 1994). La controversia existente sobre la funcionalidad de estos recipientes es un hecho conocido. Compuestos de uvas, caso de la sapa o el defrutum, o como conservantes para otros alimentos que podrían complementar al olium, como viene atestiguado en las fuentes clásicas, pueden ser los elementos transportados (Carreras, 2000, 3). Para el caso emeritense, a falta de analíticas pertinentes, podemos plantear una funcionalidad similar -vinculada a los productos vitícolas - si tenemos en cuenta todo el rosario de estructuras productivas que jalonan su territorium así como las constantes alusiones iconográficas a esta actividad (Bustamante y Cordero, 2013).

La imitación de estas piezas en un territorio alejado de su zona original no es un hecho aislado. El éxito de estas ánforas se tradujo en una fuerte imitación de las oriundas del valle del Guadalquivir en zonas cercanas, como la costa bética, caso del enclave de Puente Melchor (Puerto Real, Cádiz) o la Venta del Carmen (Algeciras, Cádiz) o ya más alejadas, como el entorno del Ródano (Desbat y Dangreaux, 1990). Para el caso lusitano también se ha documentado una producción pareja en el entorno del Sado, Abul (Mayet y Silva, 2002) y Peniche (Cardoso y Rodrigues, 2005; Fabião, 2008, 729) y se plantea la misma hipótesis para la región del Tajo con la denominada «Haltern 70 lusitana» (Quaresma, 2005). Por consiguiente, parece que estamos ante una corriente imitativa clara que acecha al occidente mediterráneo a inicios del I d.C. Incluso podemos observar una similitud en cuanto a composición de pastas y acabado externo que hace que la confusión con las producciones lusas, por ejemplo de los talleres de Peniche, sea una realidad.

En el testar localizado, más concretamente, en la cámara de combustión del horno exhumado, hemos podido encontrar una producción cerámica de carácter mixto. Este hecho parece que caracteriza a todos los complejos productivos hasta el momento hallados en la capital de la Lusitania, es decir, que no vemos una especialización de complejos productivos, sino más bien una producción regida por una amalgama de necesidades.

Las cerámicas comunes localizadas presentan rasgos morfológicos muy diversos a los que acostumbramos a ver en los contextos emeritenses más modernos -que por otra parte han sido los más estudiados-. Esto viene unido a que el momento más álgido de la producción de cerámica común se da en la segunda mitad del I d.C. y, por consiguiente, estas piezas adscritas a los primeros momentos del I d.C. no tendrían la misma difusión (como ejemplos de la variedad ver los trabajos de Alvarado y Molano, 1995 y Bustamante, 2012).

Entre las piezas comunes destinadas al consumo y preparación de alimentos encontramos a las cazuelas, que son unas de las más extendidas en el registro (Fig. 4, n. 4-6). Éstas pueden presentar bordes apuntados con leve escotadura o bien bífidos. En Mérida la producción de estos tipos no está ampliamente documentada. Esta escasez, unida a la temprana cronología, nos apunta a un momento de ensayo.

La escasa representación y, por consiguiente producción, de piezas comunes en este complejo alfarero, creemos que viene determinada por la ingente cantidad de piezas béticas que está abasteciendo y, copando, el circuito cerámico de la capital.

El grupo de las cerámicas de cocina es el predominante en los hornos de la Escuela de Hostelería. En esta ocasión, las pastas son más anaranjadas, menos depuradas, quizás para soportar altas temperaturas. Se han localizado, al menos, seis tipos diversos, que nos plantean una producción poco estandarizada de ollas:

1.- Forma globular con borde vuelto al exterior (Fig. 4, n. 1 y 3 ).

2.- Forma globular con cuello estrangulado con borde apuntado y vuelto al exterior (Fig. 4, n. 7).

3.- Forma globular con borde vuelto al exterior y pequeño resalte en el extremo del borde (Fig. 4, n. 8).

4.- Forma globular con cuello estrangulado con borde pendiente, apuntado y vuelto al exterior (Fig. 4, n. 10).

5.- Forma globular con cuello vertical y borde vertical exvasado (Fig. 4, n. 11).

6.- Forma globular con borde y vuelto al exterior con acabado redondo (Fig. 4, n. 12).

A este repertorio le tenemos que unir dolia, con bordes engrosados y pequeñas nervaduras al exterior bajo el labio (Fig. 4, n. 2). Como aderezo de algunos 

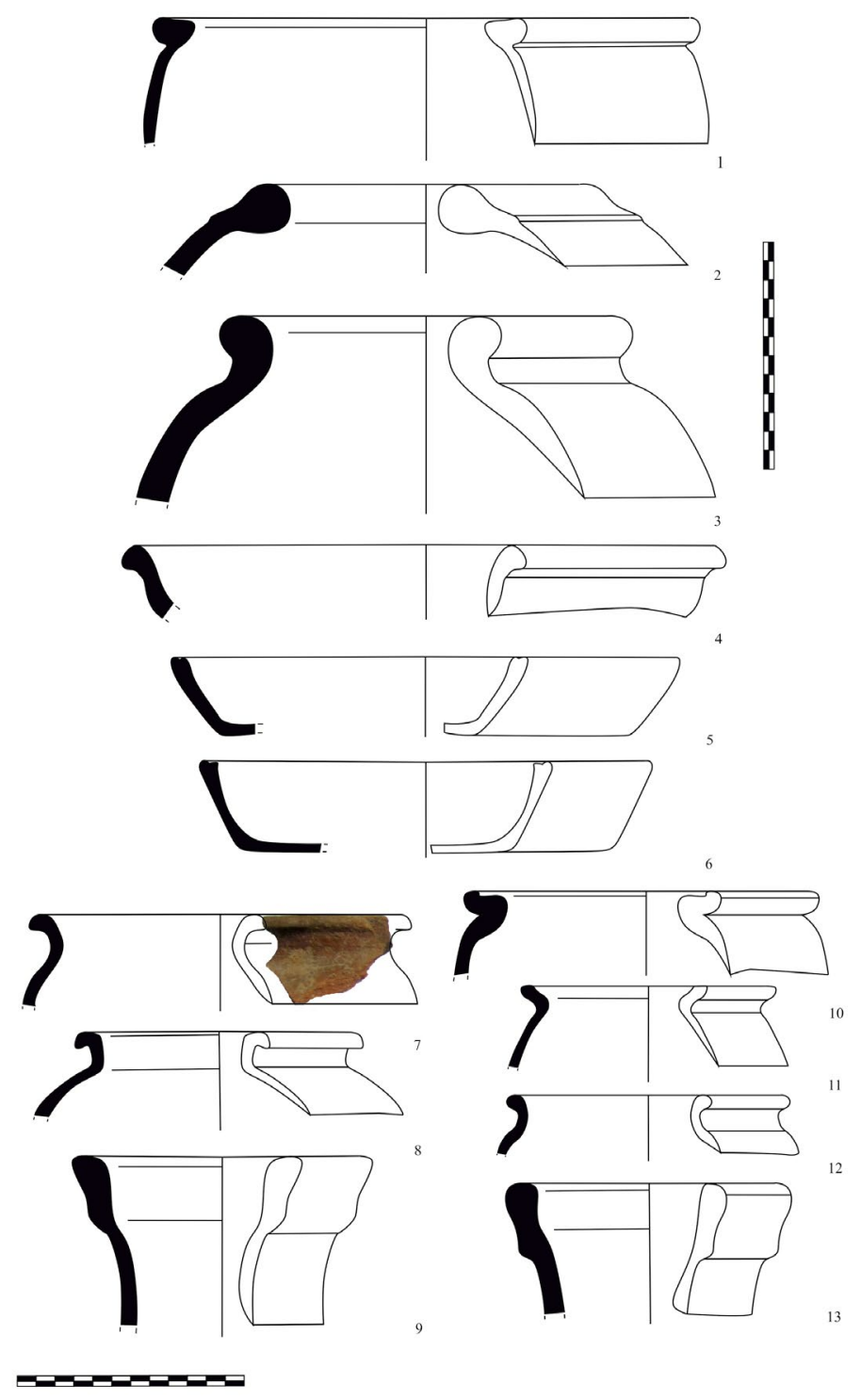

Figura 4: Cerámicas producidas en la figlina de la Escuela de Hostelería (a partir de Bustamante y Heras, 2013).

recipientes de almacenaje localizamos asas realizadas con digitaciones.

La polivalencia en los hornos emeritenses ya ha sido puesta sobre la mesa en varias ocasiones. Además de piezas vasculares destinadas al preparado, servido y consumo alimenticio, se da la producción de material edilicio. Entre el material localizado se encuentran tegulae con una o dos pestañas laterales, testae pedali, piezas horadadas en su parte central así como ladrillos cantoneros. Recordemos que Mérida fue una de las ciudades romanas que más tempranamente incluyó en su repertorio edilicio el opus testaceum (Roldán, 2008, 750 ) así en época de Claudio se observa la utilización de los ladrillos en las nivelaciones de los incerta, aumentando su uso hasta fines del V-principios del VI d.C. (Durán, 1991-92, 79, n. 95). Pero frente a esta idea de una expansión de su uso en época de Claudia, tenemos la constatación en este complejo alfarero de una ingente producción en época augustea. Esta temprana cronología iría en consonancia con la nueva hipótesis aportada por Pizzo (2010, 171-172) al considerar que su uso estaría presente en algunos edificios públicos desde época fundacional. Genéricamente la producción de material constructivo está concentrado en la primera mitad del I d.C., momento en el cual, casi toda la actividad alfarera está abocada a la erección de la ciudad.

Si comparamos los productos edilicios aportados por este complejo, presentan claras diferencias con los comúnmente extendidos y producidos en época julioclaudia avanzada. Así las pastas se presentan muy groseras, más anaranjadas y sin aparente recubrimiento externo (a modo de fina aguada blanquecina amarillenta) que sí parecen extenderse en momentos posteriores. También, en lo que concierne a las tegulae, se observan pestañas laterales muy reducidas, que quizás sean un indicativo cronológico para los primeros momentos fundacionales. 


\section{ORGANIZANDO A LOS DIFUNTOS. UN CON- TEXTO AUGUSTEO EN LA NECRÓPOLIS DE AUGUSTA EMERITA ${ }^{6}$}

Una vez valorado un contexto inserto en el núcleo más público de la ciudad y otro en una zona artesanal, terminaremos este recorrido de los primeros decenios del imperio en Augusta Emerita, analizando un conjunto cerámico parcialmente inédito de un área funeraria ubicada en el suburbio norte, más concretamente en la c/Almendralejo 41, y que ahora analizamos en profundidad.

Esta intervención presenta una diacronía muy interesante de vida entre época augustea y el siglo VIII d.C. con una sucesión de fases funcionales desde contextos funerarios, pasando por artesanales y cultuales (Heras et alii, 2011).

En esta ocasión nuestro análisis se centrará en un contexto fundacional de un mausoleo turriforme en granito de unos tres metros de altura que se encontraba jalonando uno de los flancos de la via sepulchralis que recorría distalmente dicho solar (Heras y Olmedo, 2010).

El grueso del conjunto lo conforman las cerámicas comunes de producción local-regional presentando pastas muy cercanas a las localizadas en el solar de la Escuela de Hostelería. Insistimos en una koiné morfológica de estas piezas.

Las aportaciones cronológicas del conjunto vienen dadas por las sigillatas itálicas de procedencia aretina. Entre las formas se destacan piezas del tipo Consp. 12.1 (Fig. 5, n. 1-5), Consp. 13/14 (Fig. 6, n. 7), Consp. 7.1. (Fig. 6, n. 4), Consp. 22 (Fig. 6, n. 5), Consp. 8 (Fig. 6, n. 8), Consp. 28.2 (Fig. 6, n. 9), una jarrita K7 (Fig. 6, n. 11), un fondo de Consp. 17 (Fig. 6, n. 12), dos platos indeterminados (Fig. 5, n. 6-7) o Consp. 14 (Fig. 6, n. 1, 6 y 10). De igual modo, son interesantes las formas de Consp. $32^{7}$ (Fig. 6, n. 2) así como Consp. 4.5 (Fig. 6, n. 3). Encontramos un sigillum circular en el que leemos $S \underline{A M}$ elemento solar / $P V B$ del alfarero Samio esclavo de Publius (O.C.K. $1577, \mathrm{n}^{\mathrm{o}} 5$ ) de cronología augustea y procedente del taller de Arezzo (Fig. 5, n. 8).

Otros elementos localizados son las cerámicas de imitación tipo Peñaflor de las formas Mart. Ia de procedencia bética que se presentan tanto en su variedad borde bífido como en su variedad borde apuntado (Fig. 7). Esto nos hablaría de una convivencia de tipos, al menos, en los primeros decenios del I d.C.

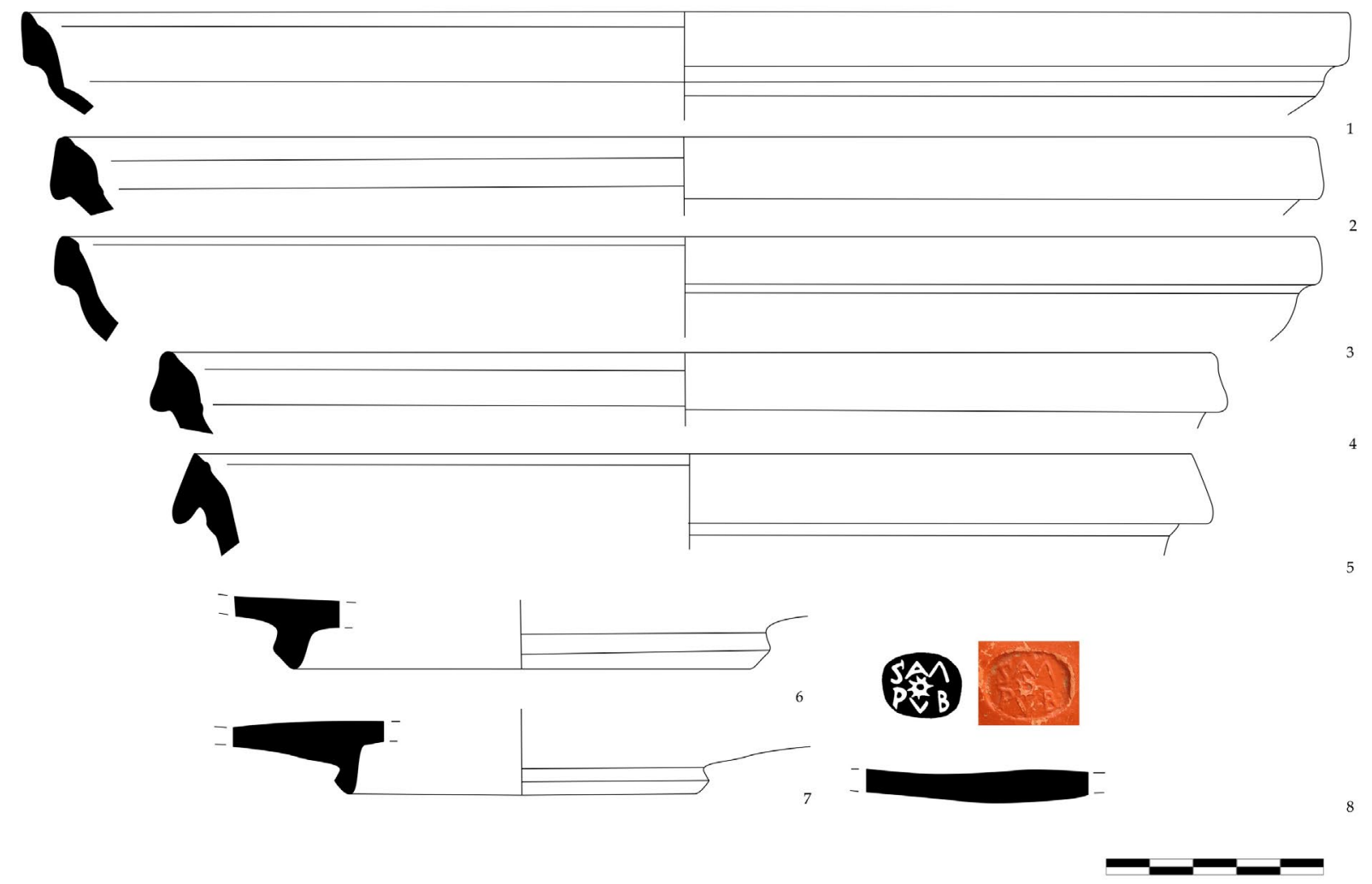

Figura 5: Sigillatas itálicas aparecidas en el contexto augusteo de la c/Almendralejo 41.

6. Este conjunto ya fue inicialmente a dado a conocer en un estudio a propósito de la sigillata hispánica (Bustamante, 2013, 39-40, lám. 1).
7. Esta pieza sería la más moderna en el conjunto con una cronología que arranca desde fines de Augusto. 


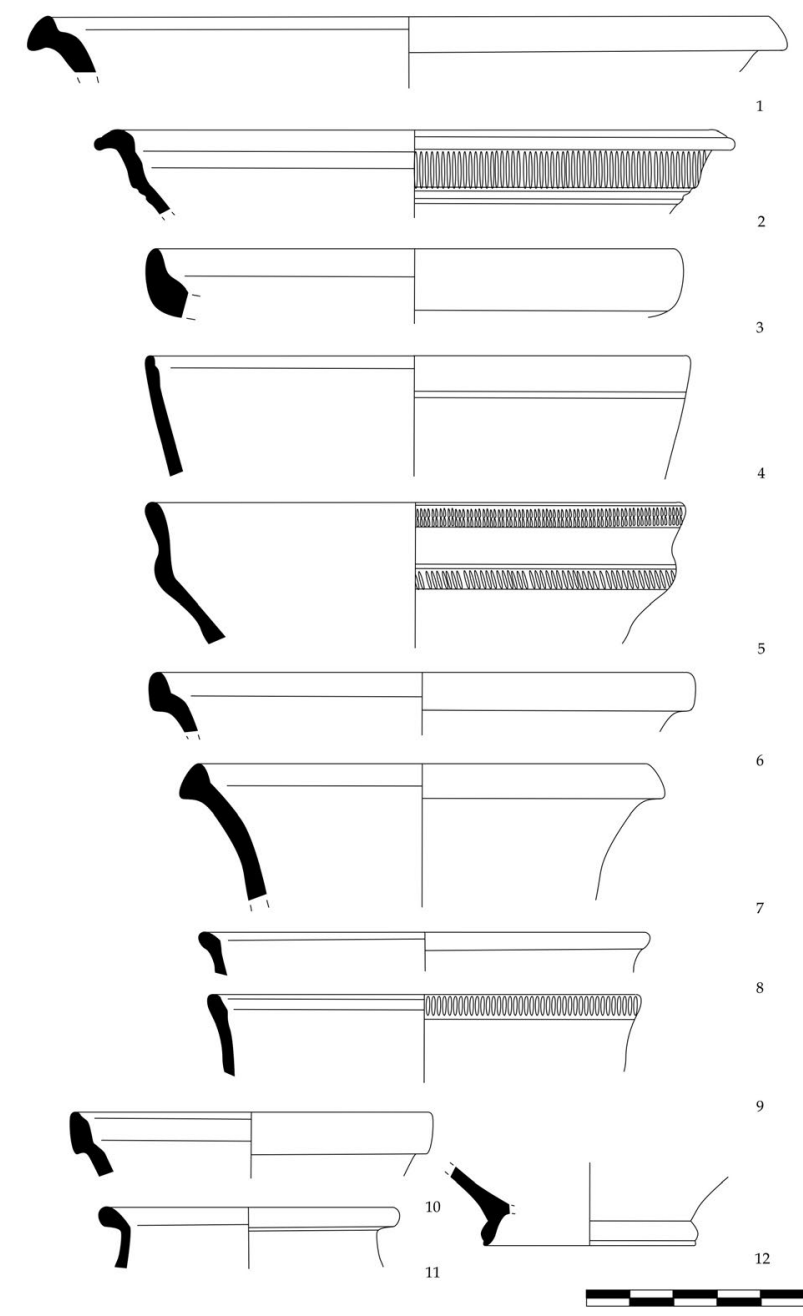

Figura 6: Sigillatas itálicas aparecidas en el contexto augusteo de la c/Almendralejo 41.

De nuevo siguen apareciendo los morteros típicos de la bética, con bordes amplios y moldurados al exterior y escalón interior (Fig. 8). Además se acompaña por un fuerte y abigarrado estriado. También de procedencia bética se han localizado algunas jarras (Fig. 9, n. 8-13) así como un cuenco (Fig. 9, n. 3). Con pastas locales, sensiblemente similares a las del taller de la Escuela de Hostelería, y con formas que también nos recuerdan a las de ese taller se encuentran ollas de borde moldurado (Fig. 9, n. 1), apuntado (Fig. 9, n. 5) y engrosados (Fig. 9, n. 6-7), lebrillos de bordes cuadrangulares (Fig. 9, n. 2) y cuencos de borde simples (Fig. 9, n. 4)

En el repertorio de piezas comunes también aparecen cerámicas pintadas a bandas vinosas y negras (Fig. 10). La matriz de su pasta es rojiza con puntos blancos y poco depurada; se aleja de las características típicas de las cerámicas locales. Aunque las piezas son fragmentarias dan la sensación de que estamos ante recipientes de mediano-gran tamaño, siendo las urnas funerarias un buen candidato al respecto. La reiteración de las bandas puede ser a líneas

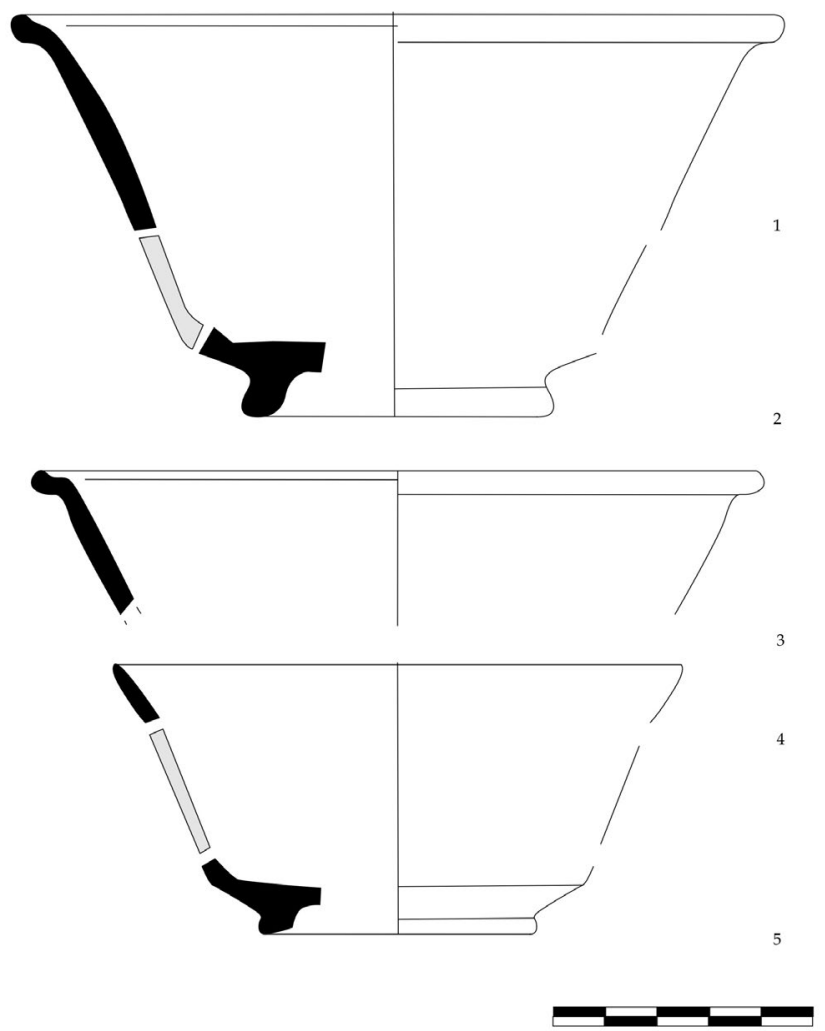

Figura 7: Cerámicas de imitación tipo Peñaflor parecidas en el contexto augusteo de la c/Almendralejo 41.

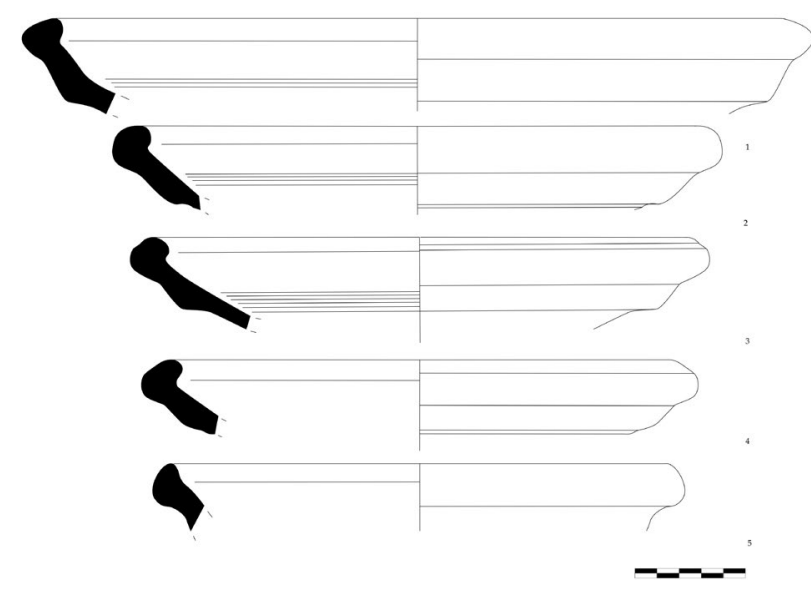

Figura 8: Morteros béticos localizados en la c/Almendralejo 41.

simples y estrechas monócromas o bícromas, alterándose franjas rojo vinoso con el propio color del barro. También habría una composición de bandas anchas bícromas con alteración de bandas negras y rojas. En general, el pigmento usado muestra poca adherencia de ahí que presenten amplias zonas sin decorar.

Junto con la vajilla común, aparecieron abundantes restos anfóricos de procedencia variada. Entre ellas se localizan algunas de procedencia campana (1'78\%), béticas con predominio de las del Círculo del Estrecho 


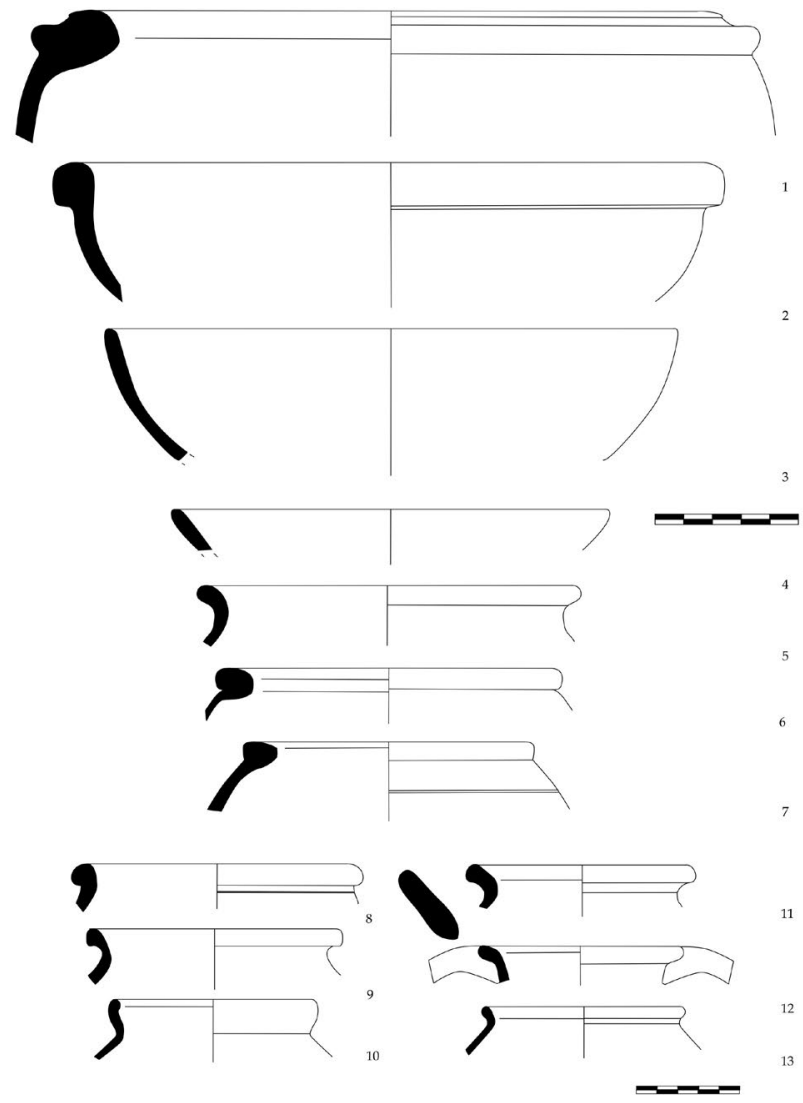

Figura 9: Cerámicas comunes localizadas en el contexto de la c/Almendralejo 41.

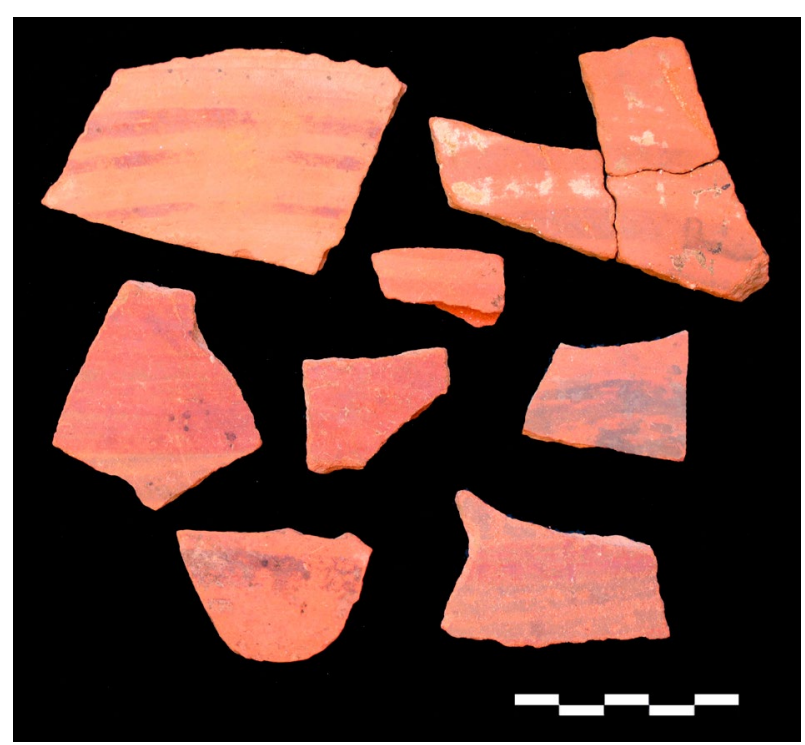

Figura 10: Cerámicas pintadas de tradición indígena localizada en el contexto de la c/Almendralejo 41.

(29'85\%), tarraconenses ( $\left.5^{\prime} 35 \%\right)$, lusitanas ( $\left.7^{\prime} 14 \%\right)$ y locales $(3,57 \%)$. Las formas anfóricas predominantes son las Dr. 7/11 (Fig. 11, n. 4-5) y las Haltern 70 (Fig. 11, n. 1-3 y 6) siendo las restantes fragmentos informes de difícil adscripción.



Figura 11: Ánforas localizadas en el contexto augusteo.

Para finalizar, dos fragmentos de lucernas; el primero es un asa con representación de vulva esquemática (Fig. 12). Morfológicamente este elemento se acopla distalmente al asa. Su forma es almendrada con incisiones paralelas triples en su interior que generan tres formas interiores. En la zona central se representa una incisión central. La forma se culmina con un pedúnculo en la zona más externa. La pasta es ocre muy clara con engobe externo anaranjado muy desgastado. Esta pieza es una de las más antiguas en el conjunto. La cronología aportada por el contexto coincide con otros conjuntos peninsulares como Ampurias (Casas y Soler, 2006, E147), Mérida (Rodríguez, 2002, lám. XIX, 1) o Herrera del Pisuerga (Morillo, 1992, lám. II).

El segundo fragmento correspondería a un disco con representación de Mercurio. Éste aparece enmarcado en un margo con abundantes delimitadores (Fig. 12). Presenta un perfil claramente griego, pelo encaracolado y culminado con un gorro acompañado por pequeñas alas laterales. Su pasta se presenta muy depurada con un fino engobe pardusco. Paralelos de esta representación los localizamos en el Museo de Mainz (Menzel, 1969, abb. 27, n. 21) o Hannover (Mlasowsky, 1993, n. 61).

Para finalizar, contamos con la aparición de una terracota de una Minerva ataviada con casco culminado con penacho superior de clara procedencia foránea (Fig. 12). Se pueden diferenciar sus cabellos que quedan distribuidos a partir de una raya central. Los ojos almendrados quedan muy diluidos, posiblemente, debido al uso excesivo del molde. Su pasta es rojiza, depurada y con fuertes fogonazos grises en su parte superior. 

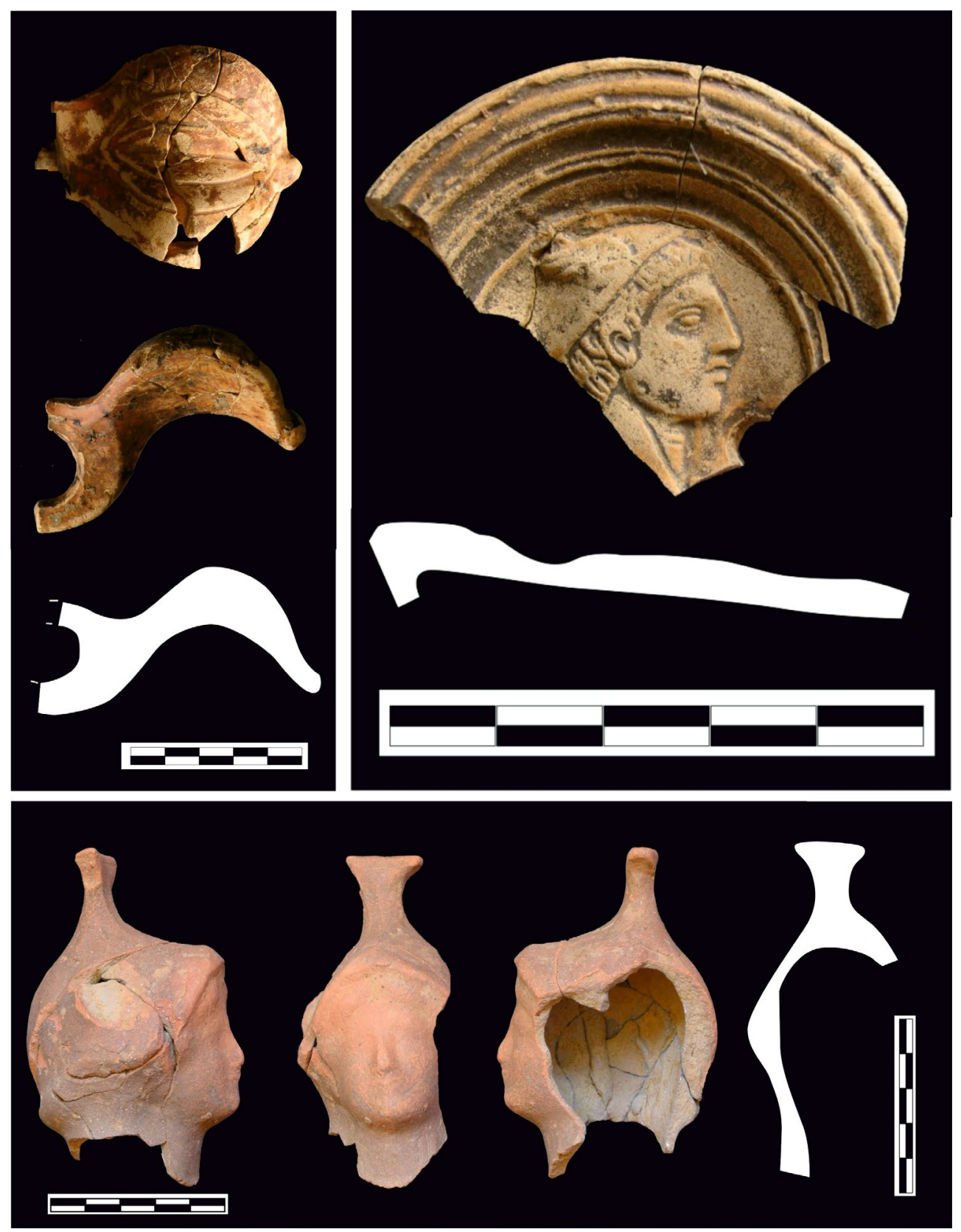

Figura 12: Lucernas y terracotas procedente del contexto augusteo de la c/Almendralejo 41.

\section{HACIA LA SISTEMATIZACIÓN DE UN SERVI- CIO AUGUSTEO EN MÉRIDA}

Una vez valorado estos tres contextos podemos afirmar que el comercio cerámico de época augustea, aunque con parcas evidencias, presenta una serie de rasgos muy significativos que parecen extrapolarse por todo su territorio como se observa en el análisis de otros contextos (Berrocal-Rangel y Ruiz, 2003 o Bustamante, 2009). Insistimos en la idea que es la primera vez que se aborda de manera monográfica un periodo, el augusteo, que fue el que asistió al nacimiento ex nihilo de este enclave y, por consiguiente, vital para comprender el devenir comercial posterior de la capital de la Lusitania.
El grueso de los conjuntos presenta cerámicas de producción local o regional. Para la producción local contamos con una figlina en el propio corazón de la ciudad que nos ofrece datos para valorar su producción, la Escuela de Hostelería (Bustamante y Heras, 2013) y, en menor medida el taller de la c/Augusto (Palma, 2004). En cuanto a los tipos comunes locales destacan las ollas y las cazuelas con fuertes aires itálicos y béticos. En el amplio repertorio de comunes locales, se aprecia la ausencia de algunas formas concretas, caso de los morteros o las jarras, los cuales se suplen a partir de su importación del foco productor bético (Sánchez, 1995, 251).

La aparición de morteros es amplia en el contexto estudiado repitiéndose el tipo característico de 
la época, conformado por una amplia solapa pegada al cuerpo del recipiente así como el estriado interior (Sánchez, 1995, 251). Su factura por pasta, amarillenta con virados verduzcos, es claramente bética.

Su aparición en contextos de la primera edad julio-claudia está atestiguado en otros puntos de la geografía de la provincia lusitania, caso de Conimbriga (Alarção, Delgado y Mayet, 1976), Mesas do Castelinho (Fabião y Guerra, 1993, 275), Castelo de Lousa (Wahl, 1985, 163) o en Braga como tipo IIA (Morais, 2004, 567).

Porcentualmente, ambos grupos productivos se reparten entre un 30\% (la producción bética) frente a un $70 \%$ (la común local-regional). Estos porcentajes no son de extrañar ante la cercanía de la provincia más romanizada del Imperio y una importante red de caminos ejemplificada en la vía de la Plata.

En lo que respecta a la vajilla fina hay un predominio claro de las sigillatas itálicas, principalmente aretinas y en un segundo grado de aparición las pisanas ${ }^{8}$.

De todo el conjunto predominan las formas Consp. $2,4,13,14$ y 22. Las piezas decoradas a moldes son muy escasas, destacándose algunos ejemplares de cálices Ritt. 5 M. Perennius y Tigranus (Jerez, 2005). Las aplicaciones así como las piezas selladas in p.p. no aparecerán en escena hasta bien entrado el reinado de Tiberio. Entre los alfareros más comunes de la época encontramos a A. Annius Crispus (OCK. 123), C. Arvius (OCK. 254), Cn. Ateius (OCK. 276), Cn. Ateius Dio(nysi) -OCK. 289-, Cn. Ateius Euhodus (OCK, 292), Sex Avillus (OCK 410), Crestus (OCK. 698), P. Cornelius con variedad de esclavos Firmus (OCK. 646), Gemellus (OCK. 648), Phileros (OCK. 664), Plocamus (OCK. 668) y Primus (OCK. 672) entre otros (Bustamante, 2011, 47) ${ }^{9}$. De la península italiana también llegan otras piezas cerámicas, como las paredes finas, sobre todo, centro-itálicas así como en menor medida algunos fragmentos de engobe rojo interno pompeyano. A pesar de esta intensa llegada de productos itálicos, existe una corriente investigadora que intenta negar este predominio inicial centro-mediterráneo arguyendo la ausencia de algunos tipos cerámicos, como las producciones campanas o las paredes finas itálicas, motivado esto por lo que denomina «efecto embudo» costero, es decir, que el grueso de las piezas quedarían en los enclaves costeros reduciendo el volumen de entrada hacia el interior (Jerez, 2005, 116). Nuestro hilo argumental, a tenor de lo analizado previamente, es totalmente el

8. Además de las piezas localizadas en estos conjuntos, existe una fuerte presencia de piezas de cronología augustea en diversos contextos dispersos por la ciudad y no, necesariamente de esta cronología (Jerez, 2005).

9. Estos sigilla, han aparecido en otras intervenciones acaecidas en suelo emeritense y ya recogidos previamente. El ser alfareros con arco productivo centrados en época augusta nos parece razón suficiente para que sean tratados de manera nominal en este trabajo. opuesto, si tenemos en cuenta que las paredes finas itálicas (destacándose los vasos tipo Aco) o las producciones comunes están presentes. Creemos que la presencia de materiales itálicos en Mérida es prioritaria en los primeros momentos de vida de la colonia (Pérez Outeriño, 1990, 140), el problema radica en saber si previo a estos niveles «tardoaugusteos» existen facies más primigenias, hecho que la Arqueología no parece confirmar.

En lo que se refiere a las cerámicas de imitación tipo Peñaflor también están presentes ampliamente, sobre todo, las formas Mart. I, clara imitación de las copas itálicas. Algunas de las piezas aparecidas en contextos augusteos fueron analizadas arqueométricamente aportándonos una procedencia de los centros béticos ${ }^{10}$, si a esto le unimos la ausencia total de evidencias arqueológicas podemos afirmar que Mérida en ningún momento produjo este tipo de piezas (Jerez, 2007). De la vajilla fina bética debemos de destacar la aparición de algunas formas en cáscara de huevo, sobre todo, de piezas de reducidas dimensiones.

En cuanto a las ánforas, las predominantes son las Dr. 7/11 así como las Haltern 70, sobre todo, procedentes del Círculo del Estrecho. Existe otro grupo amplio y numeroso en estos momentos que corresponde a las tarraconenses. En muy menor medida aparecen las primeras producciones locales de ánforas, en este caso formas variantes del tipo Haltern 70 (Bustamante y Cordero, 2013; Bustamante y Heras, 2013).

En lo que se refiere a las lucernas - uno de los tipos cerámicos más ampliamente estudiados en Mérida-, las más antiguas presentes son las Dr. 5b o Den. IVa de procedencia centro itálica y sudgálica, típicas de los reinados de Augusto-Tiberio (Rodríguez, 1996, 210). En momentos posteriores, como veremos, la intensificación de la demanda genera la apertura de nuevos talleres locales focalizados en la producción de estos objetos.

Aunque nuestro objetivo no es indagar más allá de la cerámica nos gustaría que esta aportación sirviera para reflexionar sobre la fundación de la colonia así como sus ritmos vitales, dando la sensación que la erección de la ciudad se produce de manera lenta y pausada. Esperamos que las nuevas actuaciones que se vienen desarrollando en el solar emeritense arrojen nuevos datos al respecto.

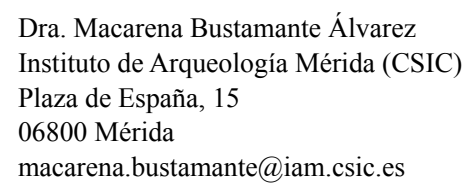

10. Analíticas realizadas por los Drs. Madrid y Buxeda para el desarrollo de nuestra tesis doctoral (Buxeda y Madrid, 2013). 


\section{BIBLIOGRAFÍA}

ALARÇÃO, J., DELGADO, M. y MAYET, F., 1976: Fouilles de Conimbriga IV, Céramiques diverses et verres, Paris.

ALBA CALZADO, M. y MÉNDEZ GRANDE, G., 2005: «Evidencias de industria paleolítica y de un alfar emeritense en Augusta Emerita. Intervención arqueológica realizada entre la prolongación de la calle Anas y el final de la Avenida Lusitania», Mérida. Excavaciones Arqueológicas, 2002. Memoria 8, 375-411, Mérida.

ALVARADO GONZÁLEZ, M. y MOLANO BRIAS, J., 1995: «Aportaciones al conocimiento de las cerámicas comunes altoimperiales en Augusta Emerita: el vertedero de la c/Constantino», en Ceràmica comuna romana d'època Alto-Imperial a la Península Ibèrica. Estat de la questió, 281-297, Ampurias.

AQUILUÉ ABADÍAS, X. y BELLO RODRIGO, J.R., 2009: «Materiales arqueológicos de los contextos constructivos y de amortización» en R. AYERBE, T. BARRIENTOS y F. PALMA, El foro de Agusta Emerita génesis y evolución de sus recintos, Anejos de AEspA LIII, Mérida.

BELLO, J.R. y MÁRQUEZ, J., 2010: «Los primeros contextos romanos de Augusta Emerita: El vertedero de los columbarios», Contextos cerámicos de época augustea en el Mediterráneo occidental (12-13 de abril de 2007), 404-442, Barcelona.

BERROCAL-RANGEL, L. y RUIZ TRIVIÑO, C., 2009: El depósito alto-imperial del Castrejón de Capote (Higuera la Real, Badajoz), Badajoz.

BUSTAMANTE ÁLVAREZ, M., 2009: «Tradición «versvs» innovación: análisis del instrumentum domesticum en el ámbito lusitano. El ejemplo del Cerro del Tesoro (La Serena, Badajoz)» en V. MAYORAL y S. CELESTINO, Los Paisajes rurales de la Romanización arquitectura y explotación del territorio, 249-270, Madrid.

BUSTAMANTE ÁLVAREZ, M., 2011: La cerámica romana en Augusta Emerita en la época Altoimperial. Entre el consumo y la exportación, Serie Ataecina 7, Mérida.

BUSTAMANTE ÁLVAREZ, M., 2012: «Las cerámicas comunes altoimperiales de Augusta Emerita», en D. BERNAL, y A. RIBERA, Las cerámicas hispanorromanas II. Las producciones regionales, 407-432, Cádiz.

BUSTAMANTE ÁLVAREZ, M., 2013: La terra sigillata en Augusta Emerita. Estudio Tipocronológico a partir de los vertederos del suburbio norte, Anejos de AEspA LXV, Mérida.

BUSTAMANTE ÁlVAREZ, M. y CORDERO RUIZ, T., 2013: «Une exportation viticole à Mérida? Considération sur la production locale d'amphores de style Haltern 70», Actas de la Conferencia Internacional Patrimonio cultural de la vid y el vino, (Almendralejo, Badajoz, 2011), 80-93.

BUSTAMANTE, M. y HERAS, F.J., 2013: «Producción anfórica en Augusta Emerita (Mérida, Badajoz) y los nuevos hallazgos del solar de la Escuela de Hostelería», en D. BERNAL, L.C. JUAN, M. BUSTAMANTE, J.J. DÍAZ y A.M. SÁEZ (Eds.), Hornos, talleres y focos de producción alfarera en Hispania, I Congreso Internacional de la SECAH Ex officina hispana, (Cádiz, 3-4 de marzo de 2011), Monografías de la Sociedad de Estudios de la Cerámica Antigua en Hispania I, 239-253, Cádiz.

BUXEDA, J. y MADRID, M., 2013: «Anexo VI. Estudio de caracterización arqueométrica de cerámicas finas altoimperiales procedentes de la ciudad romana de Emerita Augusta», en M. BUSTAMANTE, Estudio tipocronológico de la Terra Sigillata Hispánica en Augusta Emerita a partir de los vertederos del suburbio norte, Anejos de AEspA LXV, Mérida.

CARDOSO, C. y RODRÍGUEZ, S., 2005: «Olaria romana do Morraçal de Ajuda (Peniche-Portugal)», Actas do Congresso a Presença romana na Região Oeste, 83-102, Bombarral.

CARRERAS MONFORT, C., 2000: «Producción de Haltern 70 y Dressel 7-11 en las inmediaciones del Lacus Lagustinus», en Ex Baetica Amphorae, 419-427, Écija.

CASAS GENOVER, J. y SOLER FUSTE, V., 2006: Llànties romanes d'Empúries. Materials augustals i alto-imperials, Monografies emporitanes, 13, Ampurias.

DESBAT, A. y DANGREAUX, B., 1990: «La distribution des amphores dans la région lyonnaise. Etude de deux sites de consommation», en Les amphores en Gaule, 151-156, Paris.

DRAGENDORFF, H. y WATZINGER, C., 1948: Arretinische reliefkeramik, mit beischreibung der Sammlung in Tübingen, Reutlingen.

DURÁN CABELLO, R., 1991-92: «El uso del ladrillo en la arquitectura de Augusta Emerita», en M. BENDALA, CH. RICO y L. ROLDÁN (Eds.), El ladrillo y sus derivados en época romana, 205-220, Madrid.

ETTINGLER, E. ET ALII, 1990: Conspectus formarum térrea sigillata Italico modo confectae, Römisch-germanische Comisión des deutschen archäologischen Instituts zu Frankfurt, Bonn.

FABIÃO, C., 2008: «Las ánforas de Lusitania», en D. BERNAL y A. RIBERA, Cerámicas hispanorromanas. Un estado de la cuestión, 725-745, Cádiz.

FABIÃO, C. y GUERRA, A., 1993: «As ocupasões antigas de Mesas de Castelinho (Almodóvar). Resultados prelimiares das campanhas de 1990-92», Actas V Jornadas de Arqueología, II, 275-289, Lisboa.

HERAS MORA, F.J., BUSTAMANTE ÁLVAREZ, M. y OLMEDO GRAGERA, A.B., 2011: «El vertedero del suburbio norte de Augusta Emerita. Reflexión sobre la dinámica topográfica en el solar de la calle Almendralejos 41», en J.A. REMOLÁ y J. ACERO, La gestión de los residuos urbanos en Hispania, Anejos de AEspa LX, 157-180, Madrid.

HERAS MORA, F.J., JIMÉNEZ ÁVILA, J. y BUSTAMANTE ÁLVAREZ, M., e.p.: «El área alfarera del solar de la Escuela de Hostelería de Mérida. Primeras consideraciones acerca la diacronia de esta actividad productiva en la margen izquierda», Mérida, excavaciones arqueológicas, Mérida.

HERAS MORA, F.J. y OLMEDO GRAGERA, A.B., 2010: «Dos nuevos monumentos funerarios en Augusta Emerita. Primer avance de los resultados de la intervención de 
la C/Almendralejo n. 41, Mérida (Badajoz)», Bolletino di Archeologia on line, 45-53.

JEREZ LINDE, J. M., 2005: La terra sigillata itálica del Museo Nacional de Arte Romano de Mérida, Cuadernos Emeritenses 29, Mérida.

JEREZ LINDE, J.M., 2007: «La terra sigillata hispánica precoz o tipo peñaflor su incidencia en el territorio emeritense y dos marcas inéditas del M.N.A.R. de Mérida», Anas, 17, 161-178.

JIMÉNEZ ÁVILA, J.; HERAS MORA, F.J.; SÁNCHEZ CAPOTE, N. y BEJARANO, A.M., 2013: «Producción de cerâmica orientalizante en Extremadura. Estudio preliminar de los hornos de La Escuela de Hostelería de Mérida (Badajoz)», en D. BERNAL, L.C. JUAN, M. BUSTAMANTE, J.J. DÍAZ y A.M. SÁEZ (Eds.), I Congreso Internacional de la SECAH: Hornos, talleres y focos de producción alfarera en Hispania (Cádiz, 3-4 de marzo de 2011), 67-81, Cádiz.

LAVAZZARI PEDRAZZINI, Ma. P., 1987: Ceramica romana di tradizione ellenistica in Italia Settentrionale. Il vassellame «tipo Aco», Florencia.

MADRID, M. y BUXEDA, J., 2013: «Anexo VI. Estudio de caracterización arqueométrica de cerámicas finas altoimperiales procedentes de la ciudad romana de Emerita Augusta», en M. BUSTAMANTE, Estudio tipocronológico de la Terra Sigillata Hispánica en Augusta Emerita a partir de los vertederos del suburbio norte, Anejos de AEspA LXV, Mérida.

MARTIN-KILCHER, S., 1994: Die römischen Amphoren aus Augst, Bern.

MAYET, F., 1975: Les céramiques à parois fines dans la Péninsule Ibérique, Paris.

MAYET, F. y SILVA, C.T., 2002: L'atelier d'amphores de Abul (Portugal), Paris.

MENZEL, H., 1969: Antike Lampen. Im römisch-Germanischen Zentralmuseum zu Mainz, Mainz.

MLASOWSKY, A., 1993: Die antiken Tonlampen im Kestner-Museum, Museum de Hannover, Hannover.

MORAIS, R., 2004: «Os almofarizes béticos em Bracara Augusta», Figlina Baeticae. Talleres Alfareros y producciones cerámicas en la Bética romana (ss. II a.C.-VII d.C.), BAR International Series 1266, 567-570.

MORILlO, A., 1992: Cerámica romana de Herrera del Pisuerga (Palencia-España). Las lucernas, Santiago de Chile.

OXÉ, A., COMFORT, H., KENRICK, P., 2000: Corpus Vasorum Arretinorum. A Catalogue of the signaturas, Shapes and Chronology of Italian Sigillata, Bonn.

PALMA GARCÍA, F., 2004: «Secuencia ocupacional de un espacio extramuros de la Colonia Augusta Emerita. Intervención arqueológica realizada en el solar n. 44 de la calle Augusto», Mérida. Excavaciones Arqueológicas, 2001. Memoria 7, 139-155, Mérida.
PALMA GARCÍA, F., 2009: «Solar de la calle Viñeros 17», en R. AYERBE, T. BARRIENTOS y F. PALMA, El foro de Agusta Emerita génesis y evolución de sus recintos, Anejos de AEspA LIII, 331-364, Mérida.

PEINADO ESPINOSA, M. V. ET ALII, 2010: «Parque Nueva Granada: un nuevo asentamiento productivo romanorepublicano en la Vega oriental de Granada», Secah, Boletín Ex Officina Hispana, 2, 35-36.

PEREZ OUTERIÑO, B., (1990): Sellos de alfarero en terra sigillata itálica encontrados en Mérida, Cuadernos Emeritenses 3, Mérida.

PIZZO, A., 2010: «El opus testaceum en la arquitectura pública de Augusta Emerita», Archivo Español de Arqueología, 83, 147-174.

QUARESMA, J. C., 2005: «Ànforas romanas provenientes da pesca de arrasto no Tejo, depositadas no museo municipal de Vila Franca de Xira«, Revista Portuguesa de Arqueología, 8, 2, 403-428.

QUARESMA, J. C., 2006: «Almofarizes béticos e lusitanos: revisão crono-morfológica de alguns tipos», Revista Portuguesa de Arqueología, 9, 1, 149-166.

RODRÍGUEZ MARTÍN, G., 1996: «La cerámica de «paredes finas» en los talleres emeritenses», Mélanges de la Casa de Velázquez, 32, 139-180.

RODRÍGUEZ MARTÍN, G., 2002: Lucernas romanas del Museo Nacional de Arte Romano, Monografías Emeritenses 7, Mérida.

RODRÍGUEZ DÍAZ, A., 1995: «Territorio y etnias prerromanas en el Guadiana medio: aproximación arqueológica a la Baeturia Túrdula», Celtas y túrdulos: la Beturia, 205-254, Mérida.

ROLDÁN GÓMEZ, L., 2008: «El material constructivo latericio en Hispania. Estado de la cuestión», en D. BERNAL y A. RIBERA, Cerámicas hispanorromanas. Un estado de la cuestión, 749-775, Cádiz.

RUIZ MONTES, P. ET ALII, 2013: «Producción de cerámica en el ager iliberritanus hacia fines de la República: el asentamiento productivo de Parque Nueva Granada», en D. BERNAL, L.C. JUAN, M. BUSTAMANTE, J.J. DÍAZ y A.M. SÁEZ (Eds.), I Congreso Internacional de la SECAH: Hornos, talleres y focos de producción alfarera en Hispania (Cádiz, 3-4 de marzo de 2011), 307-316, Cádiz.

SÁNCHEZ SÁNCHEZ, M.A., 1995: «Producciones importadas en la vajilla culinaria del Bajo Guadalquivir», Ceràmica comú romana d'época Alto-Imperial a la Península Ibèrica. Estat de la qüestió, 251-279, Barcelona.

SCHINDLER KAUDELKA, E., 1980: Die römische modelkeramik vom Magdalensberg, Klagenfurt.

WAHL, J., 1985: «Castelo de Lousa. Ein Wehrgehöft caesarich-augusteicher Zeit», Madrider Mitteilungen, 26, 149-177. 